\title{
Arte e conhecimento: autonomização da obra de arte e verdade estética
}

Felipe Catalani

\section{Resumo:}

O presente artigo pretende esboçar a relação entre processo histórico e formação da estética enquanto forma de saber, isto é, como historicamente a arte se vincula à verdade na tradição dialética, tendo em vista principalmente as formulações de Kant, Hegel e a releitura materialista de Adorno. O diagnóstico de Peter Bürger a respeito da separação da arte da práxis vital é um ponto de partida para conceituar aquilo que veio a ser conhecido como "autonomia da arte", condição histórica fundamental para o surgimento do tipo de reflexão estética que será aqui abordada.

Palavras-chave: Estética - Dialética - Idealismo Alemão - Autonomia da Arte. 
$O$ teor de verdade das obras de arte, de que depende finalmente a sua qualidade, é histórico até ao mais profundo de si mesmo. [...] A história é imanente às obras, não é nenhum destino exterior, nenhuma avaliação flutuante. O teor de verdade torna-se histórico ao objetivar-se na obra a consciência verídica.

Theodor Adorno. Teoria estética ${ }^{\mathrm{I}}$.

Falar em verdade estética atualmente pode soar como algo caduco. Apesar disso, tendo em vista o desenvolvimento da estética como forma de conhecimento de dignidade filosófica na modernidade, que buscou superar o abismo platônico entre arte e verdade, é necessário compreender como algumas de suas categorias se desenvolvem historicamente, por mais que elas aspirem a um conhecimento supra-histórico. É inegável que Kant e Hegel, dois marcos do idealismo alemão, expressam um ponto de virada para a modernidade filosófica, sendo eles, segundo a boutade de Adorno, os últimos a tratar de estética sem entender de arte. Categorias como o belo artístico, fim/função da obra de arte e sua autonomização devem ser analisadas não somente como um desenvolvimento da filosofia da arte ou da estética, como se queira chamá-la, mas também em relação ao desenvolvimento histórico do próprio objeto dessas formas de conhecimento. Isto é um pressuposto, na visão de Peter Bürger, de uma teoria crítica da arte que se esforça para o reconhecimento de sua própria historicidade. Seu método é comparado à crítica marxiana da economia política que, em relação a categorias como o trabalho, mostra como:

[...] mesmo as categorias mais abstratas, apesar de sua validade (exatamente por causa de sua abstração) para todas as épocas, na verdade, são elas mesmas, na especificidade dessa abstração, igualmente o produto de relações históricas e possuem total validade apenas para e no interior dessas relações (MARX, in BÜRGER, 2008).

Assim, segundo a tese de Bürger, o método crítico de Marx - o qual aponta uma conexão "entre o conhecimento da validade geral de uma categoria e o desenvolvimento histórico real do âmbito almejado por essa categoria" - vale

I ADORNO, Theodor. Teoria estética. Lisboa: Edições 70, 2006. (Tradução modificada) 
também para as objetivações artísticas ${ }^{2}$. As análises empreendidas são certamente relevantes para uma compreensão histórica da constituição da estética como forma de conhecimento e de suas categorias, o que nos retira do caminho tentador das falsas ontologias e universalizações a respeito da obra de arte.

A autonomização da esfera da arte surge como uma condição fundamental para a constituição de uma apreciação puramente estética e, consequentemente, para a reflexão estética enquanto saber. $\mathrm{O}$ desenvolvimento deste processo atinge seu auge no seio da sociedade burguesa, em uma progressiva autonomização da forma e de uma consequente sobreposição desta última em relação ao conteúdo da obra de arte. É no esteticismo que a obra de arte se desvincula de toda função social até então atribuída a ela, seja na arte religiosa como função de culto, seja na arte cortesã como autorrepresentação da nobreza. O descolamento processual da arte em relação à práxis vital faz com que se cristalize "uma esfera particular da experiência (isto é, o estético) como princípio de desenvolvimento da arte na sociedade burguesa" (BÜRGER, 2008, p. 58). Na análise de Bürger, este processo só é reconhecível a partir do momento em que esta autonomia esbarra em seus próprios limites, com a autocrítica da arte exercida pelas vanguardas que, ao tentarem romper com a instituição arte, buscavam reintegrar arte e vida. Nesta cisão, Jürgen Habermas visualizou um processo inerente ao desenvolvimento do capitalismo:

A arte autônoma apenas se estabelece na medida em que, com o surgimento da sociedade burguesa, os sistemas econômico e político são desatrelados do cultural e, minadas pela ideologia de base da justa troca, as imagens tradicionalistas do mundo libertam as artes do contexto de uso ritual (HABERMAS, in BÜRGER, 2008, p. 6I).

O desenvolvimento da sociedade burguesa aparece então como uma liberação das relações sociais pré-modernas. É neste contexto que se torna possível o surgimento da própria ideia de uma arte autônoma. Filosoficamente, esta separação se dá em Kant, na cisão entre os juízos do entendimento e os juízos estéticos relativos à sensibilidade. O juízo é, em Kant, uma faculdade autônoma, uma espécie de julgamento que não se baseia em nenhuma ideia prévia, limitado à razão teórica. O juízo teleológico e o estético fazem parte da

2 É evidente que Bürger busca historicizar as categorias que ele mesmo utilizará com a finalidade de construir um aparato conceitual que dê conta de explicar a experiência das vanguardas históricas do século XX, o que não é exatamente nosso interesse aqui. 
categoria definida por Kant como juízo reflexivo, em contraposição à categoria do juízo do entendimento ou da razão. No juízo teleológico ou juízo de finalidade, Kant pressupõe o sujeito como tendo um princípio subjetivo que não está na natureza, mas na razão - tal princípio permitiria organizar a natureza como se tudo tivesse sido produzido segundo uma finalidade. Já o juízo estético possui certa regularidade entre representação e o objeto representado, mas que não serve a uma finalidade - constituindo um "juízo desinteressado" - como uma regularidade sem lei. Trata-se, então, de um princípio subjetivo a partir de uma autonomização do sentimento, em que há uma finalidade do juízo estético, cuja legalidade se dá no nível do contingente, portanto, do não necessário. Entretanto, a crítica do juízo de Kant se volta somente para a própria faculdade e percepção subjetivas, de modo que a reflexão estética se volte para o sujeito e não para o objeto, uma vez que o próprio fundamento de determinação do juízo de gosto é subjetivo ${ }^{3}$. Como base, há a dualidade entre o lógico e o estético: somente o juízo lógico é um juízo do conhecimento, enquanto o estético, a saber, o juízo de gosto, é fundado na sensação de prazer ou desprazer diante de uma representação, que não contribui em nada para o conhecimento. A arte, para Kant, não possui nenhuma relação com a verdade, pois a sua percepção é uma sensação subjetiva que não contribui nem mesmo para o conhecimento do próprio sujeito. Esta sensação subjetiva, relativa ao sentimento de prazer ou desprazer, permanece absolutamente sem mediação com o objeto. Devemos distinguir a sensação subjetiva da sensação objetiva como a percepção sensível de um objeto (juízos como "o céu é azul” etc.) que contribuem para o conhecimento. Assim, podemos ver que, filosoficamente, configura-se em Kant uma autonomia do estético no campo subjetivo como reflexo do desligamento histórico da arte de suas referências à práxis vital. Esta autonomia se realiza na definição do juízo estético como um juízo desinteressado, sendo que

3 David Hume, com sua estética do gosto, é, em certa medida, o grande antecessor de Kant. Ao realizar uma virada subjetiva, ele afirma que o belo não está nas coisas e, sim, no sujeito que as aprecia, de forma a criar uma multiplicidade de julgamentos: "Beauty is no quality in things themselves: It exists merely in the mind which contemplates them; and each mind perceives a different beauty. One person may even perceive deformity, where another is sensible of beauty; and every individual ought to acquiesce in his own sentiment, without pretending to regulate those of others. To seek the real beauty, or real deformity is as fruitless an inquiry, as to pretend to ascertain the real sweet or real bitter". HUME, David. Of the standard of taste. In: Idem. Essays, moral, political, literary. Indianopolis: Liberty Fund, I987. Apesar disso, haveria uma sedimentação do gosto, de modo que o gosto refinado é capaz de criar padrões de gosto independentemente de alguma objetividade estética. É possível certamente imaginar o contexto da apreciação cortesã de arte em salões, com tudo aquilo que o refinamento pode significar tanto filosófica como socialmente. 
Interesse é denominada a satisfação que vinculamos com a representação da existência de um objeto. Como tal, tem sempre, ao mesmo tempo, referência à faculdade-de-desejar, seja como seu fundamento-de-determinação ou, pelo menos, como necessariamente em conexão com seu fundamento-de-determinação. Mas, se a questão é se algo é belo, não se quer saber se, para nós ou para quem quer que seja, importa algo a existência da coisa, ou sequer se pode importar; mas sim como a julgamos na mera consideração (intuição ou reflexão) (KANT, I980, p. 2IO).

Ora, se o interesse está relacionado à faculdade de desejar, e o belo está desvinculado desta relação de interesse e desejo e até mesmo da existência do próprio objeto, pois o que importa é a sensação de deleite diante de sua representação, a arte ocupa então um lugar privilegiado e separado do mundo prosaico e ordinário pautado por uma racionalidade-para-fins, que é sabidamente, desde Max Weber, a racionalidade própria do mundo burguês desencantado. Consequentemente, o belo está desvinculado da satisfação de necessidades, sejam elas práticas ou espirituais. Como Bürger assinala, uma vez que a faculdade de desejar é justamente aquela que possibilita a ascensão do capitalismo, então o postulado kantiano oferece à arte uma liberdade frente às coerções da sociedade burguesa, uma vez que ela é desinteressada ${ }^{4}$. Este postulado sobre a autonomia da arte persiste ao longo da modernidade artística até sua liquidação social no capitalismo tardio, com o advento daquilo que Adorno e Horkheimer designaram com a expressão indústria cultural. O processo de mercantilização da cultura e culto da mercadoria marca o fim da autonomia da obra de arte como vinculação desta àquilo que já Kant havia chamado de interesse - neste caso, o próprio interesse de maximização de lucros, pelo lado do produtor, e o da satisfação de necessidades, pelo

\footnotetext{
4 "Se alguém me pergunta se acho belo o palácio que vejo diante de mim, posso, por certo, dizer: não gosto de coisas como essa, que são feitas meramente para embasbacar, ou, como aquele sachem iroquês, a quem nada em Paris agrada mais do que as barracas de comida; posso ainda, além disso, em bom estilo rousseauniano, censurar a vaidade dos grandes, que desperdiçam o suor do povo em coisas tão dispensáveis [...]. Tudo isso podem conceder-me e aprovar; só que disso não se trata agora. Querem apenas saber se a mera representação do objeto, em mim, é acompanhada de satisfação, por mais indiferente que eu possa ser quanto à existência do objeto dessa representação.” (KANT, Immanuel, I980, p. 2IO). A citação ilustra a concepção kantiana de desinteresse do juízo estético que, no exemplo, é desvinculada tanto do interesse do sachem iroquês, a quem interessam as barracas de comida - ou seja, um interesse voltado para a satisfação de necessidades - quanto do interesse do crítico social rousseauniano, para quem a própria existência do palácio é moralmente nefasta, caracterizando seu interesse como ligado à razão prática. Assim, o juízo estético kantiano, desprovido de todo interesse, diz respeito somente à representação do objeto e à sensação provocada por ela.
} 
lado do consumidor. Leituras culturalmente conservadoras compreendem a decadência provocada pela mercantilização da cultura, mas, entretanto, hipostasiam a autonomia da obra de arte para além de sua especificidade histórica. Nesse sentido, compreende-se a própria leitura adorniana de forma superficial, julgando-a como mera recusa elitista da banalidade da cultura de massas. Porém, Adorno e Horkheimer não fazem uma defesa abstrata da autonomia da arte, mas situam-na historicamente:

A arte como um domínio separado só foi possível, em todos os tempos, como arte burguesa. Até mesmo sua liberdade, entendida como negação da finalidade social, tal como esta se impõe através do mercado, permanece essencialmente ligada ao pressuposto da economia de mercado. As puras obras de arte, que negam o caráter mercantil da sociedade pelo simples fato de seguirem sua própria lei, sempre foram ao mesmo tempo mercadorias: até o século dezoito, a proteção dos patronos preservava os artistas do mercado, mas, em compensação, eles ficavam nesta mesma medida submetidos a seus patronos e aos objetivos destes. A falta de finalidade da grande obra de arte moderna vive do anonimato do mercado (ADORNO \& HORKHEIMER, I985, p. I30).

A autonomia da arte como condicionada historicamente é ao mesmo tempo verdadeira, pois ela se efetiva como um campo separado, e falsa, pois esta separação se dá socialmente, ocultando uma relação mais profunda que revela uma falta de autonomia. Isto constitui um caráter eminentemente contraditório da arte burguesa, fruto da incompatibilidade entre aquilo que aparece como promessa para a arte, isto é, sua liberdade frente à finalidade social, e a realização de sua liberdade como uma ausência de liberdade, dado que esta liberdade, como mostram Adorno e Horkheimer, é situada socialmente em sua dependência em relação ao "anonimato do mercado". Este é o pressuposto do que se configura como uma teoria crítica da arte, a partir da qual as obras são analisadas em sua mediação com a sociedade, no entanto sem deduzir uma a partir da outra, pois a obra de arte não reflete meramente o contexto no qual é produzida, apesar de ela manter uma relação mimética com o mundo que, entretanto, se distingue de uma relação de pura identidade. Uma teoria estética que analisasse as obras apenas do ponto de vista da reflexão ignoraria por completo a autonomia da arte enquanto processo histórico real e teria as obras como simples exemplificações, o que faria com que a própria reflexão sobre o material estético fosse inócua. No idealismo alemão, mais especificamente em Hegel, se configura uma filosofia "científica" (sem o peso dogmático que o positivismo daria a este termo posteriormente) da arte próxima à 
teoria estética adorniana, na qual o pensamento sobre o belo artístico revela uma verdade ${ }^{5}$ : em Adorno, uma verdade eminentemente social, em Hegel, relativa ao espírito ${ }^{6}$.

Hegel, na contracorrente das teorias modernas da estética do sentimento e do juízo, afirma a objetividade do belo e a necessidade da bela arte ser adequada à consideração científica. O belo pensado como uma questão do gosto pretende buscar, no juízo humano, a razão do sentimento estético, tal como no projeto moderno kantiano, em que o belo enquanto categoria do juízo seria um conceito subjetivo, reconhecido através de uma regularidade entre a "nossa representação" e o objeto representado. Nesse sentido, o conhecer é, no projeto kantiano, estabelecido como a união de representações de maneira universal e necessária; essa união é realizada $a$ priori pelo sujeito transcendental, de forma que os conceitos são dados e não produzidos. Tal circunstância do conhecer enquanto representação admite uma separação entre o conhecer e o absoluto, ou entre o saber e a coisa em si, de maneira que nisto reside um contrassenso, a saber, o de que não se pode conhecer as coisas em si mesmas. É em vista do dualismo kantiano, da separação do fenômeno da coisa em si e de sua consequente formalização e parcialidade no conhecimento, que Hegel estabelece a necessidade e a universalidade da razão em vista da totalidade do conhecer. Do mesmo modo, nos Cursos de Estética, Hegel fundamenta a necessidade de refletir sobre a bela arte enquanto objeto adequado para a consideração científica.

Hegel tem em mente que a possibilidade de consolidação de uma filosofia da arte tal como ele a formula é possível tão somente devido ao próprio desenvolvimento histórico da arte, e não a um suposto desenvolvimento independente da própria filosofia. A disponibilidade da arte para um pensamento racional é própria da época moderna, que impregna a arte - que, originalmente, "age em uníssono com o ânimo e o sentimento" (HEGEL, 200I, p. 35) - de

5 A discussão sobre o conceito de verdade estética em Adorno mereceria um texto a parte, mas o leitor terá que se contentar com uma nota de rodapé. O conceito de verdade estética em Adorno não deve ser compreendido meramente como adequação entre uma representação artística e seu objeto - isso estaria mais próximo de algo que Adorno chamaria de "correção" do que verdade propriamente dita. O teor de verdade da obra de arte em Adorno está com frequência ligado a uma relação antitética com a empiria, isto é, a negatividade é ela mesma um índice de verdade. Isto se expressa inclusive em expressões como "o verdadeiro amigo", onde "verdadeiro" não tem um caráter descritivo, e sim moral. Por esta linha de pensamento começa também a tornar-se inteligível a expressão "sociedade falsa".

6 A proximidade torna-se ainda maior se levarmos em conta a interpretação adorniana de Hegel em seu livro Três estudos sobre Hegel, mais especificamente no texto "Aspectos", onde o espírito é decifrado como trabalho social. 
universalidade, fazendo com que a obra de arte suscite, além da fruição imediata $^{7}$, um juízo pensante sobre ela, sobre seu conteúdo e seu meio, assim como sobre a relação entre ambos.

[...] a arte é e permanecerá para nós, do ponto de vista de sua destinação suprema, algo do passado. [...] A ciência da arte é, pois, em nossa época muito mais necessária do que em épocas na qual a arte por si só, enquanto arte, proporcionava plena satisfação. A arte nos convida a contemplá-la por meio do pensamento e, na verdade, não para que possa retomar seu antigo lugar, mas para que seja conhecido cientificamente o que é arte (HEGEL, 200I, p. 35).

A arte que se dispõe para o "conhecimento científico" e já não proporciona "plena satisfação" é justamente a arte separada da práxis vital, livre e subsistente em si. Caso contrário, ela não seria digna da consideração científica, como é o caso daquilo que é meramente "um jogo fugaz a serviço da diversão e do entretenimento, que adorna nossos ambientes, que torna agradável o lado exterior das relações humanas", uma arte "para fins finitos", que Hegel caracteriza não como "independente e livre, mas servil" (HEGEL, 200I, p. 32) (Grifo meu). Ora, esta arte servil é justamente aquela que predominará na indústria cultural, citada anteriormente, analisada pelos frankfurtianos. Esta arte ligeira, entretanto, ignorada por Hegel, não deixa de ser objeto de uma "consideração científica" para Adorno, que passa a analisar essas obras não mais de um ponto de vista puramente estético, imanente ao objeto $^{8}$, tal como as grandes obras de arte permitem, mas com uma abordagem eminentemente sociológica, de modo que é levado em consideração antes o modo de produção, circulação e recepção dessas obras do que sua imanência estética propriamente dita, uma vez que essas obras são determinadas de antemão pela sua característica de mercadoria e não possuem aquela autonomia necessária à consideração filosófica. A "bela arte" em sua liberdade, entretanto, se situa para Hegel na mesma esfera da religião e da filosofia, pois se torna "um modo de trazer à consciência e exprimir o divino (das Göttliche), os

7 A obra de arte na modernidade, ao ir além da fruição imediata, ganha mediação. Este conceito é fundamental para um pensamento dialético sobre a arte, que permanece em oposição a teorias kantianas que insistem em limar o momento objetivo (ou racional, na linguagem hegeliana) da experiência estética.

8 Apesar de Adorno jamais abandonar por completo o recurso à crítica imanente: a crítica adorniana ao jazz de forma alguma prescindirá da análise formal do objeto. 
interesses mais profundos da humanidade, as verdades mais abrangentes do espírito" (Idem, 200I, p. 32). Diferentemente da filosofia e da religião, a arte exprime a profundidade de um mundo extrassensível através da sensibilidade que, deste modo, a torna próxima do modo de aparecer da natureza. Este modo sensível de aparição do material artístico poderia fazer com que um filósofo, inevitavelmente tendo aprendido a lição de Descartes sobre as ilusões provocadas pelos sentidos, reprovasse a dignidade filosófica da obra de arte. Contudo, Hegel contesta que

[...] a própria aparência é essencial para a essência; a verdade nada seria se não se tornasse aparente e aparecesse [schiene und erschiene], se não fosse para alguém, para si mesma como também para o espírito em geral. Por isso, a aparência em geral não pode ser objeto de censura, mas somente o modo de aparecer segundo o qual a arte dá efetividade ao que é verdadeiro em si mesmo. [...] A arte arranca a aparência e a ilusão inerentes a este mundo mau e passageiro daquele verdadeiro conteúdo dos fenômenos e lhe imprime uma efetividade superior, nascida do espírito (HEGEL, 200I, p. 33).

Este modo de reflexão estética é próprio do pensamento dialético e seria impossível a partir de uma perspectiva kantiana, na qual o conhecimento do fenômeno (Erscheinung) permanece sem mediação com a coisa-em-si. Do ponto de vista de uma teoria do conhecimento kantiana, o conhecimento do objeto é uma projeção das categorias subjetivas, de modo que caberia conhecer, tal como foi aqui analisado brevemente, somente a faculdade subjetiva de julgar, e não a coisa-em-si, que permanece inalcançável para o conhecimento humano. A dialética, no entanto, supera o dualismo kantiano entre sujeito e objeto, tal que o em-si não permanece como em-si, e nem o para-si como um para-si, resultando em uma síntese do em-si-e-para-si como o verdadeiramente efetivo (das Wirkliche). A dialética hegeliana coloca a arte, justamente por ela ter a passagem pelo espírito, em uma posição elevada ao âmbito da verdade, oposta àquela ocupada na filosofia platônica, na qual a arte, enquanto imitação das coisas (elas mesmas já imperfeitas em relação à Ideia, de fato verdadeira), é uma mentira, um engano. Se dialeticamente a passagem pelo espírito faz com que a arte seja livre e o belo se una ao verdadeiro, a filosofia da arte só se ocupará do belo artístico, e não do belo natural, pois

[...] o belo artístico está acima da natureza. Pois a beleza artística é a beleza nascida e renascida do espírito e, quanto mais o espírito e suas produções estão colocadas acima da natureza e seus fenômenos, tanto mais o belo artístico está 
acima da beleza da natureza. Sob o aspecto formal, mesmo uma má ideia, que porventura passe pela cabeça dos homens, é superior a qualquer produto natural, pois em tais ideias sempre estão presentes a espiritualidade e a liberdade (HEGEL, 200I, p. 28).

Qualquer semelhança com a anedota de Marx, segundo a qual o pior dos arquitetos é superior à melhor das abelhas, não é mera coincidência. Em ambos está presente a concepção de que a realização da liberdade passa pela consciência e não pela natureza, seja ela no trabalho (como no caso do arquiteto em oposição à abelha), seja ela no belo artístico. Se a autonomia da obra de arte é fundamental para a constituição da estética como um saber filosófico, é preciso ter em mente que isto se dá historicamente no desenvolvimento das formas artísticas. Uma reflexão sobre o estatuto da arte e da estética na contemporaneidade não poderia simplesmente manter intactas estas categorias sem se debruçar sobre seu objeto, a saber, as próprias obras de arte. Somente no limite se faz uma teoria estética, pois ela já não pode assumir um caráter sistemático e universal. Mesmo Platão não criticou a arte como um ser abstrato e eterno, mas, sim, lidava com a arte de seu tempo ${ }^{9}$ (se já não é um anacronismo nos referir aos pintores e poetas gregos como artistas). Privilegiado ou não, não há para a arte nenhum lugar fixo insensível à história.

\section{Referências bibliográficas}

ADORNO, Theodor \& HORKHEIMER, Max. Dialética do esclarecimento: fragmentos filosóficos. Rio de Janeiro: Jorge Zahar, I985. Ästhetische Theorie. Frankfurt am Main: Suhrkamp, I973. . Teoria estética. Lisboa: Edições 70, 2006.

BÜRGER, Peter. Teoria da vanguarda. São Paulo: Cosac Naify, 2008.

HABERMAS, Jürgen. Bewußtmachende oder rettende Kritik - die Aktualität Walter Benjamins. Zur Aktualität Walter Benjamins. In: BÜRGER, Peter. Teoria da vanguarda. São Paulo: Cosac Naify, 2008, p. 6I.

HEGEL, G. W. F. Cursos de Estética I. São Paulo: Editora da Universidade de São Paulo, 200I.

9 Como mostra o estudo de Pierre-Maxime Schuhl, "Platon et l'art de son temps". Pela referência e pelas aulas sobre Platão, agradeço ao professor L. F. Franklin de Mattos. 
HUME, David. Of the standard of taste. In: Idem. Essays, moral, political, literary. Indianopolis: Liberty Fund, I987.

KANT, Immanuel. Analítica do belo. São Paulo: Abril Cultural, I980. (Coleção Os Pensadores. Textos selecionados)

MARX, Karl. Contribuição à crítica da economia política. In: BÜRGER, Peter. Teoria da vanguarda. São Paulo: Cosac Naify, 2008.

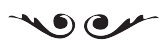

Felipe Catalani - Graduado em Filosofia pela Universidade de São Paulo em 20I5. Mestrando em Filosofia pela Universidade de São Paulo.

felipecatalani@gmail.com 